\title{
Ex vivo lung perfusion: Perfusing less lung can yield more lungs
}

\author{
Keki R. Balsara, MD, Varun Puri, MD, and Daniel Kreisel, MD, PhD
}

\footnotetext{
From the Division of Cardiothoracic Surgery, Washington University in Saint Louis, St Louis, Mo.

Disclosures: D.K. serves on The Scientific Advisory Board of Compass Therapeutics. All other authors have nothing to disclose with regard to commercial support.

Received for publication July 2, 2017; accepted for publication July 10, 2017; available ahead of print Aug 4, 2017.

Address for reprints: Daniel Kreisel, MD, PhD, Professor of Surgery, Pathology, and Immunology, Washington University School of Medicine, Campus Box 8234, 660 S Euclid Ave, St Louis, MO 63110 (E-mail: kreiseld@wustl.edu).

J Thorac Cardiovasc Surg 2017;154:e91-2

$0022-5223 / \$ 36.00$

Published by Elsevier Inc. on behalf of The American Association for Thoracic Surgery http://dx.doi.org/10.1016/j.jtcvs.2017.07.007
}

Lung transplantation remains the only durable long-term therapy for those with end-stage lung disease. The Registry of the International Society of Heart and Lung Transplantation reports that almost 4000 lung transplants were performed in 2014. ${ }^{1}$ During the past 3 decades, the field of lung transplantation has continued to evolve, with improvements in operative technique, refinements in postoperative management, and a greater understanding of donor and recipient selection criteria. Nonetheless, the field faces multiple challenges. These include but are not limited to a shortage of donor organs, a relatively high incidence of primary graft dysfunction, and a high rate of chronic graft failure.

Although progress is being made on all fronts, much of the current focus is on expansion of the donor pool. Wait list mortality has continued to increase during the recent past. $^{2}$ Moreover, donor lungs are exposed to a multitude of injurious mechanisms during the organ evaluation and donation process: ventilator-acquired pneumonia, neurogenic and hydrostatic pulmonary edema, and barotrauma. It is thus not surprising that most donor lungs are not used for transplantation. ${ }^{3}$ Expansion of the donor pool has been attempted by extending donor selection criteria, utilizing donation after cardiac death organs, and implementing ex vivo lung perfusion (EVLP). Programs are gradually adopting EVLP as a modality by which to expand the donor pool. Recent studies have suggested that outcomes after transplantation of lungs maintained with EVLP are not inferior to lungs that are not. ${ }^{4}$

In their article in this issue of the Journal, Schweiger and colleagues $^{5}$ describe the case of a 32-year-old donor with grossly normal lungs that underwent the EVLP protocol because of inferior gas exchange. During the course of perfusion, Schweiger and colleagues ${ }^{5}$ encountered isolated problems with the left lower lobe. By exclusion of this lobe through pulmonary vein ligation and ultimately surgical exclusion, they were able to perform bilateral lobar transplants successfully with a favorable outcome. Schweiger examination.

\section{References} plant. 2016;35:1170-84. 357-424.

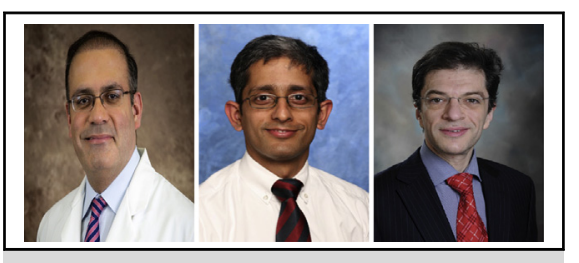

Left to right. Keki R. Balsara, MD, Varun Puri, MD, and Daniel Kreisel, MD, PhD

\section{Central Message}

Lung transplantation continues to be limited by a shortage of donor organs. Novel approaches are needed to increase the utilization of lungs for transplantation to expand the donor pool.

See Article page e87.

and colleagues ${ }^{5}$ appropriately speculate on the mechanism by which their approach proved successful. They propose that clamping and exclusion of the donor lobe during EVLP eliminates shunting and therefore facilitates evaluation of donor lung quality. More intriguing is their contention that isolation of the injured lobe might impede the dissemination of proinflammatory cytokines and bacteria to the rest of the circuit and the normal lung parenchyma. There is increasing evidence to suggest that cytokine release at the time of procurement and reperfusion might adversely impact outcomes after lung transplantation.

In the final analysis, Schweiger and colleagues ${ }^{5}$ describe an ingenious modification of currently accepted EVLP protocols that may affect the field. Through the early identification of a suboptimally performing lobe, they were able to isolate that lobe and complete the EVLP process. This resulted in a usable graft for their recipient. As the wait list expands, the field must continue to look for means by which to increase the donor pool. The technique described by Schweiger and colleagues 5 in this article has proved safe and efficacious in one patient and deserves closer

1. Yusen RD, Edwards LB, Dipchand AI, Goldfarb SB, Kucheryavaya AY, Levvey BJ, et al. The Registry of the International Society for Heart and Lung Transplantation: thirty-third adult lung and heart-lung transplant report-2016; focus theme: primary diagnostic indications for transplant. J Heart Lung Trans-

2. Valapour M, Skeans MA, Smith JM, Edwards LB, Cherikh WS, Uccellini K, et al OPTN/SRTR 2015 annual data report: lung. Am J Transplant. 2017;17(Suppl 1): 
3. Valapour M, Skeans MA, Heubner BM, Smith JM, Schnitzler MA, Hertz MI, et al. OPTN/SRTR 2012 annual data report: lung. Am J Transplant. 2014;14(Suppl 1): 139-65.

4. Tikkanen JM, Cypel M, Machuca TN, Azad S, Binnie M, Chow CW, et al. Functional outcomes and quality of life after normothermic ex vivo lung perfusion lung transplantation. J Heart Lung Transplant. 2015;34:547-56.

5. Schweiger T, Benazzo A, Lang G, Matilla JR, Klepetko W. Selective lobar exclusion by venous clamping during ex vivo lung perfusion. J Thorac Cardiovasc Surg. 2017; 154:e87-9. 